\title{
Transformation of Surgical Training Through National Transformation 2050 (TN50): A National Agenda
}

\section{Razman J}

Department of Surgery, Faculty of Medicine, Universiti Kebangsaan Malaysia Medical Centre, Jalan Yaacob Latif, Bandar Tun Razak, 56000 Cheras, Kuala Lumpur, Malaysia.

\section{Introduction}

Surgical training worldwide has been reformed from the since 19th century until the present era. It started as a trade which eventually was transformed into a profession that acquires skills and knowledge. The apprenticeship model was introduced amongst the Western surgeons as the standard approached for surgical training. The surgery was learned through direct observation without any formal and structured education. William S Halstead had introduced the new approach of training the surgeons in America following his landmark lecture at Yale University in 1904 (1). His principle was based on direct the German Surgical training which emphasized on basic sciences in the curriculum and Sir William Ossler concepts of bedside rounds. This has lead to the development of Halsted principals of surgical training which included intense and repetitive exposure in managing surgical patients under the supervision of skilled surgeons, acquiring the knowledge of scientific basis of surgical diseases and as the surgical trainee received enhanced responsibility and independence with each advancing year (2). Since then, Halsted principle of surgical training has become the foundation of most established surgical training worldwide. The principles have been expanded and upgraded and since then six cores competencies have been identified for the surgical residents to achieve and master during the training course (3). There were medical knowledge, patient care, interpersonal and communication skills, professionalism, practice-based learning and improvement and system based practice.
From the Malaysia perspective, surgical training was done through the overseas Royal colleges after the independence in 1957. The local programme started in 1982 through the initiative of local universities that initially offered surgical training programme in General surgery, Orthopedics and otorhinolaryngology (4). Since then through the collaborations of Ministry of Health and other professional bodies various surgical training programme has been established to provide training opportunities which will eventually serving the nation. The subcommittee of the National Conjoint Board for General Surgery was the consultative body to oversee and manage the implementation of the surgical training. Since the establishment, the subcommittee was responsible in streamlined the training curriculum for all the universities that offered the course, centralized and standardized the intake of the trainees, coordinating the national exit examination and advising new application for graduate training in general surgery. The important milestone of the subcommittee was the task given to develop the national surgical postgraduate curriculum for the doctors who are interested in becoming a surgeon in the country. The curriculum is being developed to create a pathway for surgical training from the internship until subspecialty training. The development encompasses the governance, the curriculum development, the training process and learning outcome according to the latest evidence based on post graduate training. The programme should be the foundation in producing well trained surgeons towards 2050 through TN50. National transformation 2050 or TN50 is an initiative 
to plan for the future of Malaysia towards 2050. It is a process of transformation from vision of becoming a developed nation into the process to be amongst the top countries in the world in economic development, citizen well-being and innovation.

\section{Challenges}

As the plan towards TN50 is underway, new challenges surface for the surgical training. The expanding of surgically related diseases and development new therapies had lead to bigger challenges to the educators. The emerging of new surgical skills like laparoscopic surgery and robotic surgery had changed the paradigm of surgical training. This new entity requires new development of in approaches particularly in providing training and assessment of effectiveness of the training. With ever increasing expansion of patient awareness and knowledge about their health, the surgical trainees need to be equipping with the necessary skill and knowledge. In recent years simulation through skill training stations has been shown to be effective for skill training and critical thinking. Courses like ATLS and Crisp course allow the trainees to be exposed and acquire the familiarity to the real life scenarios hence improving skill transfer. It also allows objective evaluation of the trainees as well as direct feedback on their performance as surgical trainees. Simulators can also be used for improvement of surgical technical skills. Through the advancement of technology, state of the art virtual reality simulators allows the trainees to have a repeated procedure being done hence improving learning and efficiency. The system allows evaluation through competence based advancement and without patients at risk.

Assessment of the surgical trainees is also an important integral part in developing sustainable and quality surgical training programme. Presently the main criteria of assessment are passing the exit exam that was held at the end of year 4 of surgical training. An additional assessment through objective assessment is also a valuable tool in transforming surgical education. It can be used as part of continuous assessment to evaluate the trainees performance as they progress over the years of training. A development of such structured skill performance Journal of Surgical Academia Oct 2017;7(2):1-3 assessment with certain benchmarks level enables the trainers to evaluate the trainee more efficiently. Furthermore, this will allow the surgical trainees to gauge themselves in achieving specific procedural goals according to the given curricula. As for the trainers, such structured performance curricula would allow them to monitor the trainees individually according to their actual performance progress based on the specific goals. This will allow them to tailor the training module to the individual trainees need and able to give more dynamic feedback on their performance. Efforts are underway to develop such curricula through the National surgical curriculum review and this may lead to opportunities for more training places that are able to fulfill the requirements.

As part of the process toward striving into innovative nation and improving the wellbeing of population towards TN50, workforce planning need to be reviewed in more constructive manner. This includes the development of more training centre for surgical trainees. Presently training is available at the university hospitals and major general hospitals. Utilization of other medical centers including specialist available district hospitals and army hospitals need to be considered. However, it has to be done in the proper planning in order to prevent the imbalance between the training and service provision of such centre.

\section{Conclusion}

Overall the surgical training in Malaysia is undergoing revision as we are moving towards 2050. The programme development curriculum should produce surgeons who are able to take full responsibilities towards patient care, equip adequate knowledge and skills to meet the challenges of the 21 st century. This will ensure the surgeons produce through the programme are competent and able to achieve greater heights.

\section{References}

1. Nguyen L, Brunicardi FC, Dibardino DJ, et al. Education of the modern surgical resident: novel approaches to learning in the era of the 80-hour workweek. World J Surg 2006; 30(6): 1120-7. 
2. Grillo HC. To impart this art: the development of graduate surgical education in the United States. Surgery 1999; 125(1): 1-14.

3. Swanson AG. The genesis of the Coordinating Council on Medical Education and the Liaison Committee on Graduate Medical Education. Bull N Y Acad Med 1974; 50(11): 1216-21.

4. Lokman S. Enhancing Surgical trainingMalaysian perspective. J Surg Acad 2011; 1(1): $1-5$. 